
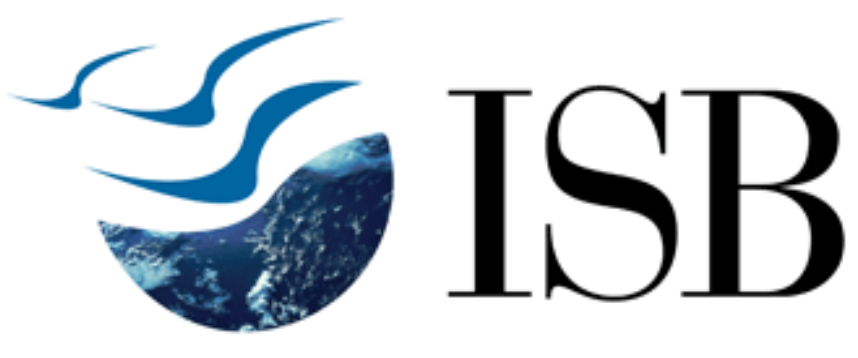

\title{
Good IPOs draw in bad: Inelastic banking capacity and hot
}

\author{
Markets
}

http://eprints.exchange.isb.edu/102/

Article

Indian School of Business

2008 


\title{
Good IPOs draw in bad: Inelastic banking capacity and hot markets $^{\dagger}$
}

\author{
Naveen Khanna \\ Eli Broad School of Business \\ Michigan State University \\ Thomas H. Noe \\ Saïd Business School and Balliol College \\ University of Oxford \\ Ramana Sonti \\ Indian School of Business
}

This version: January 2007

\begin{abstract}
We posit that screening IPOs requires specialized labor which, in the short run, is in fixed supply. Hence, a sudden increase in demand for IPO financing increases the compensation of IPO screening labor. Increased compensation results in reduced screening which encourages sub-marginal firms to enter the IPO market, further increasing the demand for screening labor and thus its compensation. The model's conclusions are consistent with empirical findings of increased underpricing during hot markets, positive correlation between issue volume and underpricing, negative correlation between issue volume and information production, and with tipping points between hot and cold markets characterized by discontinuous jumps in volume, underpricing, and issue quality. Finally, the model makes sharp and so far untested predictions relating IPO market conditions both to the fundamental values of IPO firms and to the returns to investment banks and investment banking labor.
\end{abstract}

JEL Classification Codes: G20, G24; Keywords: IPO, underpricing, labor constraint

\footnotetext{
${ }^{\dagger}$ We wish to thank Walid Busaba, Mike Fishman, Jie Gan, Jon Garfinkel, Anand Goel, Vidhan Goyal, Gerard Hoberg, Yrjo Koskinen, Erik Lie, Ji-Chai Lin, Tim Loughran, Allen Michel, Jacob Oded, Gordon Phillips, Thomas Rietz, Harley "Chip" Ryan, Jay Sa-Aadu, Paul Schultz, Ann Sherman, Mark Taranto, Xianming Zhou, seminar participants at Baruch College, Boston University, DePaul University, Louisiana State University, MIT, Michigan State University, Notre Dame University, University of Iowa, University of Maryland, University of Michigan, University of Minnesota and the University of Western Ontario, as well as the discussant and participants at the 2005 City University of Hong Kong Corporate Finance and Governance Conference for their valuable comments and suggestions. Special thanks are extended to the Editor, Matthew Spiegel, and two anonymous reviewers for very detailed and insightful comments. The second author, Thomas Noe, would also like to acknowledge the generous support and assistance of the Sloan School at MIT, where he was a visiting scholar during the period in which much of the work on the manuscript was completed. All remaining errors are ours.
} 


\section{Introduction}

Extensive research on Initial Public Offerings (IPOs) has documented that on average issues are underpriced and that underpricing is significantly higher during hot markets. For instance, during 1999-2000, average first day IPO returns were an astonishing 65\% compared to a more normal 15\% for the rest of the 1990s. ${ }^{1}$ Surprisingly, not only did such high underpricing fail to discourage new issues but, as documented by Lowry and Schwert (2002), issuance volume actually increased. If underpricing were related to uncertainty regarding issue quality as in most rational models of IPOs, and uncertainty is higher during hot markets, one would expect increased investment by banks in information generation to mitigate this problem. Yet, Ljungqvist and Wilhelm (2003) and Corwin and Schultz (2005) document that information production per issue, as measured by the size of the underwriting syndicate, fell significantly during the 1999-2000 hot market. ${ }^{2}$ Moreover, not only was IPO underpricing very different during this hot market, so were the characteristics of IPO firms. Ljungqvist and Wilhelm document that the median hot market issuing firm was substantially younger and less profitable at the time of issue and that median pre-offer insider ownership was significantly lower, suggesting that either by design or compulsion, the average IPO pool appears to be inferior during this period.

Taken together, the evidence of less search during hot markets, a positive correlation between underpricing and issue volume, and lower average quality of new issues is difficult to reconcile with traditional rational-agent information production models of IPO pricing. ${ }^{3}$ This has led authors like Loughran and Ritter (2002) to develop behavioral explanations for why IPO firms "leave so much money on the table" during hot markets. Their analysis implicitly assumes, in addition to behavioral assumptions about the preferences of the owners of IPO firms, a friction blocking competition between banks. Otherwise banks would compete with each other for this money and in the process eliminate rents from underwriting. Even if newly wealthy entrepreneurs with low marginal values for IPO proceeds were willing to accept prices substantially below fundamental values, they would presumably prefer leaving a bit less if offered a better deal by competing investment bankers. This inability to provide a competition-proof explanation for observed empirical results suggests that an important variable specific to hot markets may have been overlooked in existing models and that its inclusion could reconcile the

\footnotetext{
${ }^{1}$ See Loughran and Ritter (2002).

${ }^{2}$ Both papers reconcile this apparent contradiction using the argument proposed in Benveniste, Busaba, and Wilhelm (2002) that reduced information production might result from greater commonality across IPOs during hot markets, optimally requiring less information collection. However, that should result in lower underpricing and a better quality IPO pool during hot markets, results not supported by empirical evidence. This suggests that the commonality of bunched IPOs is not the complete explanation.

${ }^{3}$ See, for example, Rock (1986), Allen and Faulhaber (1989), or Benveniste and Spindt (1989).
} 
apparently contradictory findings.

To identify a potentially omitted variable, we look to the labor market of project screeners whose skill is essential to identifying project quality. We argue that in the face of positive IPO demand shocks, banks/underwriters have to access this market to hire additional screeners. We also argue that screening IPOs is a complex process which requires specialized labor that takes time to train. Therefore, in the short run, such labor is in fixed supply. This single constraint of inelastic supply of screening labor can have a considerable effect on the behavior of IPO markets. ${ }^{4}$ When the demand for IPOs shifts up, either because of a technical innovation requiring investments in new production activities or because of temporal variation in the market price of risk (see Pastor and Veronesi (2005)), it meets a less than perfectly elastic supply of screening capacity. The resultant equilibrium must thus feature an increase in the compensation of screening labor and the lowering of screening standards. Realizing this, lower quality issuers act to exploit the reduced quality of screening by entering the IPO market, further increasing the size of applicant pool and putting even greater strain on screening capacity and wages. ${ }^{5}$ The result is a lower quality pool of IPOs. This interplay between average screening quality and expected quality of IPOs determines how many firms with bad projects enter the IPO market and the average amount of underpricing in the economy. Since the higher underpricing and higher demand for IPOs comes from a finitely lived constraint in the labor market, not only does higher underpricing persist, but there is a positive correlation between underpricing and issue volume.

The adjustment process posited in this model yields a number of very sharp predictions. These predictions all revolve around how shocks, either to the potential profitability of projects in the economy or to the overall level of economic activity, affect the fundamental characteristics of IPO firms, the underpricing of IPOs, the volume of IPO activity, the compensation of investment banking labor, and profits to the shareholders of investment banks. The most direct predictions of the model, those which flow directly from the inelastic supply of investment banking capacity are that

- Information search per project (measured, for instance, by syndicate size) will be

\footnotetext{
${ }^{4}$ Thus this paper is related to recent work by Michelacci and Suarez (2004) on venture capital in that they, like us, focus on how inelastic factor supplies affect the efficiency of capital markets. They find that, in the face of an exogenous increase in capital demanded, the cost of venture capital increases, leading entrepreneurs to exit venture funds earlier.

${ }^{5}$ In a seminal piece, de Meza and Webb (1987) capture similar overinvestment in bad projects when there is credit rationing. By refusing credit to marginally profitable projects, banks improve the quality of borrowing firms and lower the average interest rate charged. This makes it more attractive for bad firms to enter. Ruckes (2004) also develops a model that explains the variation in screening over the business cycle. His analysis unlike ours is not based on inelasticity of screening labor supply, but on changes in the ex-ante characteristics of the applicant pool.
} 
lower during hot markets.

- Investment banking labor compensation will be higher in hot markets.

Because of these higher costs, we predict that the quality of screening is worse in hot markets. Thus, controlling for pre-IPO characteristics, post IPO issue quality will be worse and more variable. This logic implies the following predictions

- Hot market IPOs will have lower and more variable economic profits.

- Hot market IPOs will have lower chances of survival.

Because of less screening in hot markets and more entry by marginal projects, underwriters will underprice more and produce less information. This yields the following predictions.

- Underpricing in hot markets is significantly higher than in cold markets.

- Issue volume and underpricing are positively correlated.

- The long-term performance of IPOs issued during hot markets is more variable.

In our analysis the natural metric for the aggregate volume of activity is the total after-market price of all issues. Because investment banks earn rents from underwriting due to their bargaining power vis à vis firms, the more deals banks do, the higher the returns to their shareholders. At the same time, because a larger fraction of the deal's rents are extracted by their employees, the marginal gain from deal volume is falling. Hence we predict that

- aggregate investment bank profitability from IPOs is a concave function of the aggregate level of IPO activity.

Perhaps the most stringent test of our analysis is that it predicts that IPO pricing cycles are based on constraints to aggregate investment banking capacity. Thus, we predict that when the constraint is tightest, hot market effects are most pronounced. This reasoning produces the following predictions.

- Local shocks confined to specific industry IPOs will produce little IPO underpricing.

- Underpricing will decrease and search per project will increase with the maturing of the hot market as more capacity comes on line. 
Finally, because of the discontinuous nature of the shift from cold to overheating IPO markets, we predict that

- the nature of the equilibrium shifts abruptly in IPO markets, with issue quality and underpricing changing dramatically when the market transitions into a hot market.

While some of these hypotheses have been tested, others are new. Moreover data is available on the quality of IPO firms across issue markets. Ljungqvist and Wilhelm identify distinguishing characteristics like lower average age, profitability and insider ownership for the IPO pool during the 1999-2000 hot market. While these are consistent with the pool being inferior, a more direct test should compare actual long term operating profits and survival rates of IPO pools from all hot and cold markets. Another distinct test is whether, controlling for long run underperformance, long run market performance of pools from hot markets is more variable. ${ }^{6}$

Benveniste, Ljungqvist, Wilhelm, and Yu (2003) document that an increase in initial returns is associated with a reduction in underwriter rank and ascribe that to a reduced need for underwriter certification when investors are more willing to pay high prices for IPOs. ${ }^{7}$ Our paper suggests an alternative hypothesis: given that higher initial returns and volume are positively correlated, the move towards lower ranked underwriters is due to capacity constraints at the better underwriters. The two explanations also have starkly different predictions about underpricing. While our explanation predicts higher underpricing during hot markets, theirs is more consistent with lower underpricing. They ascribe this to the presence of a common information component across IPOs bundled close in time and industry, reducing the quantity of information needed. However, if the demand shock is not only firm specific but economy wide, inelasticity of labor supply should bind, increasing the price of information generation. Thus, whether such bundling results in reduced cost of information collection should depend on whether the price or quantity effect dominates.

These predictions are based on a very simple model of IPO issuance at the firm level. We assume that the underwriter's objective is to maximize the offer price (and thus their fees through the gross spread), subject to a penalty that is positively related to

\footnotetext{
${ }^{6}$ Since long run underperformance of issues during hot markets has been documented to be higher, return variability is likely to be higher for that reason. However in our model the first day closing price is an unbiased expectation of firm value, so there is no long run underperformance. The higher long run variability in returns comes from a larger proportion of bad projects in the pool of accepted projects. To isolate this effect some control for long run underperformance may be necessary.

${ }^{7}$ The presumption appears to be that high initial returns and high price levels are correlated. Given that higher underpricing and higher volume during hot markets, and equity issue volume being higher when prices are high, this appears consistent.
} 
the extent of overpricing. As we show in Appendix B, our key insights hold in other underpricing frameworks as Rock (1986). This robustness to model specifics should not be surprising because the basic dynamic in the IPO market that drives our analysis is that uncertainty regarding issue quality is costly to issuers, and can be reduced through screening. This sort of dynamic is featured in many IPO models. ${ }^{8}$ Thus, the contribution of this paper is not to identify and model a new tension in the IPO issuance process, but rather to identify the implications of a rather standard tension at the individual IPO level for aggregate IPO market behavior when the price of screening is endogenous and the supply of screening capacity is restricted.

The rest of the paper is organized as follows. In Section 2, we outline the basic structure of our model. In Section 3, we develop our parametric assumptions. We establish some useful basic results in Section 4. In Section 5, we present detailed analysis of an equilibrium featuring IPO underpricing in a tight labor market. Section 6 concludes the paper. Appendix A contains formal proofs of all results in the paper. Appendix B demonstrates that our key insights can also be obtained when underpricing is modeled as in Rock (1986).

\section{The Model}

\subsection{Overview}

The main players in this model are entrepreneurs and underwriters (investment banks). We model firms as projects owned by entrepreneurs, each of which has a terminal payoff of $\tilde{X}$. Projects can be of two types, Good $(G)$ with a payoff of $\tilde{X}=1$, or $\operatorname{Bad}(B)$ with a payoff of $\tilde{X}=0$. The total number of projects (the project pool) in the economy is $N$. Since this is a one-period model, entrepreneurs cannot delay or postpone undertaking projects. At the beginning of the game, it is common knowledge that the fraction of $G$ projects in the economy is $\rho$, and that the fraction of $B$ projects is $1-\rho$. Project quality is the private information of the entrepreneurs. Underwriters can screen projects through the use of skilled labor. The quality of the appraisal depends on how much labor is employed. We assume a continuum of underwriters. Each underwriter can underwrite one project.

Firms wishing to raise equity in the IPO market apply to underwriters (this subset of firms is hereafter called the applicant pool). Once a firm is matched with an underwriter, neither side has an exit option. Thus, the division of the proceeds from the underwriting

\footnotetext{
${ }^{8}$ See for example the costly dissemination model in Welch (1989), the legal risks model of Hughes and Thakor (1992) or the incentive payments for information revelation in Benveniste and Spindt (1989) and Cornelli and Goldreich (2001).
} 
process is determined through a bilateral bargaining process. Following Hermalin and Katz (1991) for example, rather than model the extensive form bargaining game, we simply assume that bargaining results in a split of the proceeds between the firm and the underwriter, with a fraction $\beta$ being captured by the firm and the remaining $1-\beta$ by the underwriter. ${ }^{9}$ This assumption is reasonable in the context of this paper given the evidence in Chen and Ritter (2000) of remarkably constant underwriter spreads.

Underwriters who were matched with a firm hire screening labor, negotiate over proceeds with their firm, apply screening labor and, finally, set offer prices. The entrepreneur who controls the firm has an opportunity cost of $w$ for issuing an IPO. This cost could represent, for example, the value of the time required to form an IPO company, develop a business proposal, meet with bankers etc. For convenience, we assume that the opportunity cost for entrepreneurs of both $B$ and $G$ projects is the same. This assumption is not crucial for our results. What is required is that the net gain from undertaking the project is higher for $G$ projects. This assumption represents a very simple case of the single-crossing property typical of signaling/screening models - the better type, $G$, has a larger marginal gain from undertaking the action, issuing, than the lower quality type, $B$.

Screening labor is hired in a competitive labor market that works as follows. Underwriters pick a quantity, $\eta$, of skilled labor they intend to hire. Since underwriters take the price of screening labor as fixed, the cost of hiring $\eta$ quantity of skilled labor is simply $\eta \theta$, where $\theta$ represents skilled labor's rate of compensation. As is standard in a competitive equilibrium, although each underwriter acts as if he can purchase an unlimited quantity of skilled labor at the price $\theta$, the aggregate supply of skilled labor is fixed at a constant level. Aggregate supply and demand for skilled labor are equated through the price of skilled labor, $\theta$. We normalize the aggregate supply of skilled labor to 1 unit. Because we allow the size of the project pool to vary, and because equilibrium prices are unaffected by multiplying both the supply of labor and the number of projects by a common positive factor, this normalization is made without any loss of generality. Given the assumption that the supply of labor is 1 unit, the tightness of the labor market is measured by the size of the project pool, $N .^{10}$

Screening produces a random signal $\tilde{s}$, which can take values of either $H, L$, or $U$. The conditional distribution of the signal based on true quality is given as follows:

\footnotetext{
${ }^{9}$ See Hermalin and Katz (1991) for a discussion of the rationale for this reduced form approach.

${ }^{10}$ Note that, instead of assuming that the underwriter hires only skilled labor in restricted supply, we could have assumed that the underwriter chooses a fraction $\eta$ of skilled labor with the remaining labor for screening the issue coming from unskilled labor in perfectly elastic supply at a wage of 0 .
} 


\begin{tabular}{cccc}
\hline$x$ & $P(\tilde{s}=H \mid \tilde{X}=x)$ & $P(\tilde{s}=L \mid \tilde{X}=x)$ & $P(\tilde{s}=U \mid \tilde{X}=x)$ \\
\hline 1 & $\eta$ & 0 & $1-\eta$ \\
0 & 0 & $\eta$ & $1-\eta$ \\
\hline
\end{tabular}

The assumed signaling structure implies that if an underwriter buys $\eta$ quantity of labor, the underwriter receives a perfectly uninformative signal, $U$, with probability $1-\eta$ and a perfectly informative signal, $H$ or $L$ with probability $\eta$. More general structures, which are tractable only through numerical analysis, yield similar results. In our set-up, $\eta$ represents both the quantity of labor purchased by the underwriter and the quality of the signal received by the underwriter. We also assume that the signal produced by the underwriting process is publicly observable, or equivalently, that the underwriter cannot misreport the signal. In the equilibria we identify, under very mild restrictions discussed later, it is not in the interest of the underwriter to report a higher signal than the signal she observes. Thus, the assumption is made without too much loss of generality. Although the realized signal is public information, the quality of labor used by the underwriter to produce the signal is private information. After observing the signal, the underwriter fixes an IPO price, and this price determines the proceeds from the issue.

After the IPO is priced and issued, the cash flow from the project is realized. This cash flow determines the post-issue price of the IPO. If price drops in the after-market, the underwriter bears a penalty proportional to the square of his realized profit from selling the issue to outside investors, i.e., we assume a penalty of the form $\gamma(1-\beta)(\max [p-x, 0])^{2}$. This formulation is based on the litigation costs from overpricing IPOs as in Hughes and Thakor (1992). ${ }^{11}$ In a dynamic model where underwriters develop reputations based on their ability to identify good projects, underwriters would also bear a cost from setting an issue price higher than the after-market value. However, our key results do not hinge on assuming a reputational or legal penalty for underpricing but can also be derived in a Rock (1986) adverse selection framework. We show this in Appendix B. ${ }^{12}$

The following timeline illustrates the sequence of actions in this model.

\begin{tabular}{|c|c|c|c|c|c|}
\hline 0 & 1 & 2 & & 3 & 4 \\
\hline $\begin{array}{l}\text { Projects } \\
\text { and under- } \\
\text { writers } \\
\text { matched }\end{array}$ & $\begin{array}{l}\text { Under- } \\
\text { writers } \\
\text { purchase } \\
\text { screening } \eta\end{array}$ & $\begin{array}{l}\text { Firms } \\
\text { apply to } \\
\text { under- } \\
\text { writers for } \\
\text { screening }\end{array}$ & $\begin{array}{l}\text { Screening } \\
\text { results in } \\
\text { signal } \tilde{s}\end{array}$ & $\begin{array}{l}\text { Price } \\
\text { setting } \\
\text { and } \\
\text { bargaining }\end{array}$ & $\begin{array}{l}\text { Project } \\
\text { cash flows } \\
\text { realized }\end{array}$ \\
\hline
\end{tabular}

\footnotetext{
${ }^{11}$ For evidence on litigation risk and IPO underpricing, see Lowry and Shu (2002).

${ }^{12}$ We can also establish this result in the less standard ambiguity aversion framework of Easley and O'Hara (2005). Details are available from the authors upon request.
} 
See Table 1 for a summary description of all variables in our model.

\section{Parametric assumptions and equilibrium}

In order to focus on interesting sections of the parameter space, we impose the following restrictions.

Assumption $12 \gamma(1-\rho) \rho>1$.

Assumption $2 \beta \rho>w$.

Assumption $3 N \rho>1$.

Assumption 1 ensures that an uninformed underwriter has an incentive to underprice the IPO when all $B$ entrepreneurs are trying to obtain financing. Assumption 2 ensures that the reservation payoff of entrepreneurs is low enough that unless the IPO is underpriced, all $B$ entrepreneurs will want to issue when there is no screening. Assumption 3 ensures that the (inelastic) labor supply is insufficient to screen all good projects perfectly. Essentially these three assumptions exclude regions of the parameter space where (a) entrepreneurs with bad projects obtain financing without generating any underpricing or inducing any screening by the underwriter (b) entrepreneurs with bad projects "self-screen" by staying off the market even when fairly priced, and (c) there is a sufficient supply of screeners to perfectly screen all projects at a labor wage rate of zero. Analyzing these excluded cases is not difficult but would be tedious and would produce few, if any, surprising results.

In our analysis, an equilibrium is a 4-tuple consisting of an issue strategy for the entrepreneurs, a pricing strategy for underwriters, screening labor demand and a wage for screening labor. As we will verify later, in any Perfect Bayesian equilibrium, the equilibrium issue strategy calls for all entrepreneurs with $G$ projects to issue. Thus, the analysis of the strategy choice of the entrepreneur can be reduced to considering the fraction of $B$ entrepreneurs that issue. We call this fraction $\alpha$. As we will also easily verify in the following analysis, it is optimal for the underwriter to set a price of 1 after a $H$ signal and a price of zero after a $L$ signal; thus the underwriter pricing strategy can be reduced to fixing a price upon observing an uninformative signal $U$. We call this price $p_{U}$. The underwriter's other decision is the quantity of skilled labor to purchase, $\eta$. In making this decision, the underwriter takes the labor wage, $\theta$, as fixed. 


\section{Model solution}

Solving our model requires deriving equilibrium conditions both in the IPO market and the screening labor market; in fact, the interaction between these markets is the focus of our analysis. To control modeling complexity we have adopted very simple specifications for both markets. Nevertheless, solving the model is complicated by the number of steps involved. Working backwards, the first step is to determine the underwriter's optimal IPO policy, i.e., the quantity of skilled labor and the level of underpricing. The underwriter's solution is conditioned on her signal, $H, L$, or $U$, the expected quality of the firms choosing to perform IPOs, and the price of underwriting labor. The underwriter takes these parameters as given.

At the same time owner-entrepreneurs make a decision on whether to attempt an IPO. This decision is predicated on their private information regarding IPO quality, the pricing decision they expect from the issuer, and their conjecture regarding the quantity of underwriting labor. Fixing the price of underwriting labor we solve for a Perfect Bayesian equilibrium in the underwriter owner-entrepreneur game satisfying standard equilibrium refinements. This yields the equilibrium fraction of firms that seek IPO financing, the extent of underpricing, and the demand for underwriting labor. By varying the price of skilled labor, a demand curve for labor is generated, which when intersected with labor supply curve generates the overall equilibrium for our model. Finally, we perform comparative statics to examine how in IPO/labor market equilibrium, shocks to the labor demand and/or quality of the project pool affect underpricing and the quality of the applicant pool.

\subsection{Price setting and underwriter payoffs}

Before we analyze the various equilibria in this model, we derive the optimal offer price, and the expected payoffs of entrepreneurs and underwriters, taking as constant the quality of screening, $\eta$, and the proportion of $B$ projects that apply for screening, $\alpha$. Underwriters are risk neutral and thus maximize their expected payoff, which equals their fraction of issue proceeds less expected costs generated by a possible ex post price drop. Thus the underwriter's payoff, excluding payments to skilled labor, which are fixed at the time the pricing decision is made, as a function of the signal she receives and the price she sets is given by

$$
v(p, s, \eta)=(1-\beta) p_{s}-(1-\beta) \gamma E\left[(\max [p-x, 0])^{2}\right]
$$

Under our assumed signal structure, with probability $1-\eta$ the underwriter receives an 
uninformative signal. At the time the pricing decision is made, the underwriter's skilled labor purchase decision has already been made. Thus, the only remaining decision is the pricing of the issue. Moreover, because the signal is public information, sequential rationality on the part of (risk neutral) investors implies that the issue price cannot exceed the expected value of the issue. If the $U$ signal is from a $G$ project, it will not be overpriced ex post. If it is from a $B$ project, there will be overpricing since the postissue price will equal the issue's true value, 0 . Thus the underpricing penalty will equal $\gamma(1-\beta)(p-0)^{2}$. Because the $U$ signal is uninformative, probabilities conditional on a $U$ signal equal unconditional probabilities. Thus when the signal is uninformative, the underwriter solves

$$
\begin{array}{r}
\max _{p_{U}}(1-\beta) p-(1-\beta) \gamma p^{2}(1-\pi), \\
\text { s.t. } p \leq \pi,
\end{array}
$$

where $\pi$ represents the probability that an entrepreneur attempting to obtain funds has a good $(G)$ project. ${ }^{13}$ Given the concavity of the objective function in $p$, problem (1) has a straightforward solution, ${ }^{14}$

$$
p_{U}^{*}(\pi)=\min \left[\frac{1}{2 \gamma(1-\pi)}, \pi\right] .
$$

Within this pair of solutions, $p_{U}=\frac{1}{2 \gamma(1-\pi)}$ is the underpricing solution. Given Assumption 1 , we know that at $\pi=\rho$, the underpricing solution is optimal. This fact, the fact that $\frac{1}{2 \gamma(1-\pi)} \rightarrow \infty$ as $\pi \rightarrow 1$, and the convexity of $\frac{1}{2 \gamma(1-\pi)}$ together imply that there exists a unique $\pi^{\text {up }}$ such that for $\rho \leq \pi<\pi^{\text {up }}$ underpricing is optimal and for $\pi>\pi^{\text {up }}$ pricing at expected value, $\pi$, is optimal. Solving explicitly for $\pi^{\text {up }}$ (and using Assumption 1) yields

$$
\pi^{\mathrm{up}}=\frac{1}{2}+\sqrt{\frac{1}{2}\left(\frac{1}{2}-\frac{1}{\gamma}\right)},
$$

and

$$
p_{U}^{*}(\pi)= \begin{cases}\frac{1}{2 \gamma(1-\pi)} & \text { if } \pi \in\left[\rho, \pi^{\mathrm{up}}\right] \\ \pi & \text { if } \pi \in\left[\pi^{\mathrm{up}}, 1\right] .\end{cases}
$$

\footnotetext{
${ }^{13}$ Thus, $\pi=\frac{\rho}{\rho+\alpha(1-\rho)}$.

${ }^{14}$ Note that by imposing the condition in (2), we are assuming that the underwriter cannot sell the issue at a price higher than its true expected value $(\pi)$ to outside investors. This rational expectations condition is not required for any of our results, which are derivable assuming that investor reservation prices for IPO participation are based on non-rational sentiment based models. However, given that our results are consistent with rational behavior on the part of IPO investors we feel that, for parsimony, it is reasonable to derive our results within the rational investor paradigm.
} 
The expected payoff from the issue, excluding the cost of skilled labor is given by

$$
V_{U}^{*}=(1-\beta)\left[p_{U}^{*}-\gamma p_{U}^{* 2}(1-\pi)\right] .
$$

With probability $\eta$, the underwriter receives a perfectly informative signal of the value of the entrepreneur's project. The probability of a perfectly informative signal being $H$ equals the probability of a good project, $\pi$, and the probability of the perfectly informative signal being $L$ equals the likelihood of a bad project, $1-\pi$. In the case of a perfectly informative $H$ signal the risk of ex post overpricing is zero and thus the underwriter will set a price equal to value of 1 . In the case of the perfectly informative $L$ signal, the highest price the market will pay is zero. Thus, when an underwriter receives the perfectly informative signal, her payoff, excluding the cost of screening labor, is

$$
V_{I}^{*}=(1-\beta) \pi .
$$

Thus, the expected payoff to the underwriter given the purchase of $\eta$ quantity of screening labor, at a wage rate $\theta$ is given by

$$
V^{*}(\eta)=\eta V_{I}^{*}+(1-\eta) V_{U}^{*}-\theta \eta .
$$

\subsection{The entrepreneur's payoffs}

If the entrepreneur has a $G$ type project, then for an informative signal, the issue price is 1 , and for an uninformative signal, the issue price is $p_{U}^{*}$. Thus the expected payoff to an entrepreneur deciding to issue with a $G$ project is

$$
E_{G}(\eta)=\beta\left[\eta+(1-\eta) p_{U}^{*}\right] .
$$

With a $B$ project, the payoff to the entrepreneur will equal zero when screening is informative, and $p_{U}^{*}$ when it is not. Thus,

$$
E_{B}(\eta)=\beta\left[(1-\eta) p_{U}^{*}\right]
$$

\subsection{Basic results}

Proposition 1 In any Perfect Bayesian equilibrium satisfying standard refinements, entrepreneurs with good projects issue with probability 1.

Given Proposition 1, the strategy choice of entrepreneurs can be summarized simply by the probability a $B$ entrepreneur attempts to issue. We will represent this probability 
by $\alpha$. Next we show that, in equilibrium, underwriters always choose an interior level of screening labor demand, strictly between the maximum and minimum levels.

Proposition 2 In any Perfect Bayesian equilibrium satisfying standard refinements, the quantity of skilled labor purchased by the underwriter is strictly between 0 and 1 .

Note that since the underwriter is choosing an interior level of labor demand and because the labor demand is linear in $\eta$, we must have $V^{* \prime}(\eta)=0$ in any equilibrium. We see from inspection of equation (8) that this first-order condition is equivalent to the condition

$$
V_{I}^{*}-\theta=V_{U}^{*}
$$

Using these results allows us to present the equilibrium conditions for the model in a very succinct form. First note that Bayes rule implies that there is a one-to-one mapping from $\alpha \in[0,1]$ to $\pi \in[\rho, 1]$ the equilibrium probability that an issuing firm is a $G$ type. Thus, we can use $\pi$ as the state variable representing the issuance strategy of $B$ entrepreneurs instead of $\alpha$. Note that screening labor demand, given by $N \eta[\rho+\alpha(1-\rho)]$, by Bayes rule, is equal to $N \eta \rho / \pi$.

\section{Equilibrium in overheating IPO markets}

In this section, we present the analysis of an IPO market where the demand for screening labor is sufficient to allow labor to earn economic rents; screening discourages some but not all $B$ projects from attempting to obtain IPO funding and because of the cost of screening labor, screening is imperfect and issues are underpriced. We call such IPO markets "overheating markets." It is easy for us to examine other equilibrium configurations. For example, if the supply of potential projects is sufficiently small, then we can find equilibria where screening is cheap, the screening labor market is slack and labor market effects do not matter. One could term such a market, a "cold market." It is also possible for the supply of projects to be so large and screening to be so poor that all projects regardless of their quality attempt to obtain funding. In this case, any further pressure on the IPO market from labor supply has no effect on issue quality. One might term such markets "cooked markets." However, for parameters generating such equilibria, many of the effects we are interested in discussing are not present. Thus, to keep the paper centered on our most interesting results, we focus on overheating markets and the transition from cold to overheating markets. ${ }^{15}$

\footnotetext{
${ }^{15} \mathrm{~A}$ complete analysis of all possible equilibrium configurations for this model is available from the authors upon request.
} 
In an overheating market, the labor market equilibrium condition equates demand with inelastic supply. This labor market equilibrium condition determines the labor wage $\theta$, and screening is only partially effective in that not all $B$ projects are kept off the IPO market. In such an equilibrium, $B$ entrepreneurs must be indifferent between issuing and not issuing. We formally define such an equilibrium as a triple $(\pi, \eta, \theta)$ satisfying the equilibrium conditions of sequential rationality, market clearing and underpricing as follows.

$$
\begin{aligned}
\beta(1-\eta) p_{U}^{*}(\pi) & =w, \\
N \eta \rho & =\pi, \\
V_{I}^{*}(\pi)-\theta & =V_{U}^{*}(\pi), \\
\text { and } \pi & \in\left[\rho, \pi^{\mathrm{up}}\right] .
\end{aligned}
$$

The first condition in (12) states that the expected payoff to a $B$-firm is the same if it attempts or does not attempt an IPO. This assumption makes $B$-firms the marginal entrants to the IPO market. The second condition equates the supply and demand for screening labor. To understand the second condition better, note first that $\eta$ is the quantity of labor demanded by each individual investment banker. Since all investment bankers are identical, $\eta$ also represents the average intensity of screening for projects. In the overheating market equilibrium all good types attempt to obtain IPO financing and $\alpha$ fraction of bad types also attempt IPOs. Thus, the likelihood a given project attempts to obtain financing is given by $\rho \times 1+(1-\rho) \times \alpha$. For this reason, the total number of projects that attempt to obtain financing equals $N(\rho+(1-\rho) \alpha)$. Because the average screening intensity for a project attempting to obtain financing equals $\eta$, aggregate quantity of screening demanded equals $N \eta(\rho+(1-\rho) \alpha)$. Average project quality, $\pi$, equals $\rho /(\rho+(1-\rho) \alpha)$. Thus we can express screening demand as $N \eta \rho / \pi$. For the screening labor market to clear we must have aggregate demand $N \eta \rho / \pi$ equal the exogenously fixed supply of screening labor. This supply, by assumption equals 1 unit. Thus, labor market clearing is represented by the second condition of (12). The third condition in (12) ensures that the price of investment banking labor $\theta$ equals its value to investment banks. The final condition ensures that the quality of the pool of IPO applicant firms is such that underpricing is optimal in the absence of effective screening.

\subsection{Informal analysis}

We now have the key drivers of our analysis in place and hence, can preview our most puzzling result - the negative relation between the average quality of potential IPOs in 
the project pool, $\rho$, and the actual IPOs in the IPO market, $\pi$. The first driver for this result is that the higher the average quality of IPOs issued, the higher the gain from issuing for $B$ firms. Second, since a $B$ firm's chance of being identified is increasing in the intensity of screening, its payoff is falling in the amount of screening labor in the IPO market. These two drivers imply that if we plot an indifference curve for $B$-firms in the space of the average IPO quality $(\pi)$ and screening labor employed in the aggregate, the curve will be upward sloping. The third driver is a very simple version of the single crossing property satisfied in our model - the marginal gain from issuance is higher for $G$ firms. This single crossing property implies that all $G$ firms must issue whenever any $B$ firms issue.

Thus, in an overheating market equilibrium, for any fixed level of screening labor, a higher proportion of good projects in the project pool implies more projects that require screening and hence a lower chance for any given project being screened properly. Thus, if we raise the fraction of $G$ firms in the pool, we make the IPO market uniformly more attractive to $B$ firms. This shifts the indifference curve of the $B$ firms outward as shown in Figure 1. In this figure, the indifference to entry curve for $B$ firms is plotted in project screening - applicant pool quality space. The two lines representing indifference are represented by $\mathcal{I}^{\prime}$ and $\mathcal{I}^{\prime \prime}$, where $\mathcal{I}^{\prime \prime}$ represents $B$-firm's indifference curve at the higher quality project pool. The fourth and last key driver of our analysis is the inelastic supply of screening labor represented by the dashed vertical line $\mathcal{S}$. In the overheating market equilibrium, $B$ firms must be indifferent to entry and thus the $B$-firm indifference curve $\mathcal{I}$ must intersect $\mathcal{S}$. When the quality of the project pool $\rho$ improves and thereby shifts the indifference curve out, indifference can be restored only by lowering the expected IPO price of $B$ firms, which, given the inelastic supply of screening labor, requires that expected price after an uninformative signal fall. However, a fall in the IPO price, given rational expectations, requires that the actual quality of IPOs, $\pi$, falls. Thus, increasing the quality of potential IPOs lowers the quality of IPOs undertaken, i.e., an increase in good projects available drives so many bad projects onto the IPO market that the overall quality of issues is worse than it was before the increase.

Of course, this argument has a lot of loose ends at this point, e.g., formally proving that all the curves have the required continuity and the shapes claimed above, as well as teasing out many other results of the model for underpricing, labor compensation, and aggregate volume of IPO activity. We tie these up in the subsequent analysis. However, the fairly simple logic presented here should at least assure the reader that even our most puzzling result is not the product of artificial assumptions or technical legerdemain. 


\subsection{Analysis}

In this equilibrium, $p_{U}^{*}=\frac{1}{2 \gamma(1-\pi)}$. Using equation (12), we can write

$$
\eta^{*}=1-\frac{2 \gamma w\left(1-\pi^{*}\right)}{\beta} .
$$

Substituting from (13) into (12), we have

$$
\pi^{*}=\frac{N \rho(2 \gamma w-\beta)}{(2 \gamma w N \rho-\beta)}
$$

Using (12), we can write

$$
\begin{aligned}
\theta^{*} & =V_{I}^{*}\left(\pi^{*}\right)-V_{U}^{*}\left(\pi^{*}\right), \\
\text { which reduces to } \theta^{*} & =(1-\beta)\left[\pi^{*}-\frac{1}{4 \gamma\left(1-\pi^{*}\right)}\right] .
\end{aligned}
$$

Using the solution for $\pi^{*}$ from (14), it is straightforward to prove that the range of project pool size within which there exists an overheating market equilibrium is as follows.

$$
\begin{aligned}
& N_{1}^{\text {up }}<N<\frac{\beta}{\beta-2 \gamma w(1-\rho)}, \\
& \text { where } N_{1}^{\text {up }} \text { solves } \pi^{*}=\pi^{\text {up }} \text {. }
\end{aligned}
$$

See Appendix A for details.

\subsection{Project quality, underpricing and the labor market}

We next examine key comparative statics. In particular, we wish to examine the effect of varying $N$, the size of the project pool, and $\rho$, the ex ante proportion of $G$ projects in the population, on the equilibrium values of average IPO quality and expected underpricing. Recall that a market featuring a high value of $N$ corresponds to what the empirical IPO literature calls a "hot" market. In other words, we wish to contrast expected underpricing in hot and cold markets through an examination of the comparative statics with respect to $N$. Also of interest is the quality of the average IPO during hot versus cold markets. Finally, we also wish to examine how changes in the ex ante distribution of projects quality affect expected underpricing and average IPO quality. For instance, does an increase in the proportion of $G$ projects in the economy translate to a higher average quality IPO? The following results summarize the answers to these questions. 
Before we proceed to examine these comparative statics, we provide definitions of average IPO quality and expected underpricing in terms of the parameters of the model.

\section{Definition 1}

$$
\text { Average IPO quality, } A Q=\pi \text {. }
$$

Note that $\pi$ is also the probability that an entrepreneur attempting to obtain funds has a good project.

\section{Definition 2}

$$
\text { Expected underpricing, } E U=(1-\eta)\left[1-\frac{1}{2 \gamma \pi(1-\pi)}\right] \text {. }
$$

This definition of expected underpricing follows from the fact that underpricing occurs only when the underwriter receives an uninformative signal. Also, note that we have defined underpricing as a percentage of the fair price $\pi$. This measure corresponds to the way underpricing is usually defined in the empirical literature.

The following propositions summarize the effect of changing project pool size on average IPO quality and expected underpricing.

Proposition 3 In an overheating market equilibrium, average IPO quality decreases with any further increase in size of the project pool.

This suggests that, empirically, we should on average observe lower IPO quality during hot markets when labor supply is more likely to be constrained, and lower survival rates for these IPOs. Also, since the decrease in the average IPO quality comes from a larger proportion of $B$ projects applying and getting accepted, the ex-post profitability of the IPO pool should be lower.

The intuition behind Proposition 3 is straightforward. As the total number of available projects increases, screening worsens on average. This encourages $B$ projects to enter IPO market, and average IPO quality, $\pi^{*}$, falls. This proposition is illustrated in Figure $2 .{ }^{16}$

We now turn to expected underpricing. First, note that the fall in IPO quality with an increase in the size of the project pool is accompanied by a reduced likelihood of effective screening. Second, it turns out that expected underpricing is related not only to the quality of the IPO pool, but also its variance. If the fall in average IPO quality also increases the variance of quality, then the risk associated with issuing an IPO without

\footnotetext{
${ }^{16}$ For this figure and all the subsequent ones, the specific numerical solutions used to generate the results are available upon request. The relations are robust to wide range of parameter choices.
} 
effective screening also increases. Both these effects lead to an increase in expected underpricing. This happens when the project pool consists of a larger proportion of $G$ projects. On the other hand, if the fall in average IPO quality decreases the variance of quality, then underpricing may decrease in the size of the project pool. This is the case when the pool consists of a larger proportion of $B$ projects. This intuition is summarized in the following proposition.

Proposition 4 In an overheating market equilibrium, when an increase in the size of the project pool leads to an increase in the variance of IPO quality, expected underpricing increases. A sufficient, but not necessary, condition for the variance to increase with project pool size is that at least half the projects are good.

The empirical implications of this proposition are straightforward. As long as screening is somewhat effective in limiting the entry of negative net present value $B$ projects into the IPO market, an increase in the number of potential projects will increase the market's uncertainty regarding project quality and raises underpricing.

To understand why the composition of the project pool is important, consider the definition of underpricing given by Equation 18. In this expression, the term $\pi(1-\pi)$ represents the variance of the value of issues with uninformative signals. This variance has a unique maximum at $\pi=1 / 2$. This implies that the underpricing of an issue screened as a $U$ project also has a unique maximum in applicant pool quality at $1 / 2$. In the overheating market equilibrium, applicant pool quality lies between the quality of project pool, $\rho$, and 1 . Thus, if $\rho \geq 1 / 2$, underpricing is decreasing in applicant pool quality over the entire range of feasible applicant pool quality $[\rho, 1]$. Proposition 3 ensures that an increase in size of the project pool $N$ decreases applicant pool quality. Thus, when $\rho \geq 1 / 2$, underpricing will increase with the size of the project pool. When $\rho<1 / 2$ the situation is more subtle. In this case, since sufficient $B$ types have already entered the IPO market to drive average quality below the variance maximizing level of $1 / 2$, further entry of $B$ types lowers the variance of issue quality and thus reduces the underpricing of uninformatively screened issues. Thus, one effect of an increase in the size of the project pool is to decrease the underpricing of issues screened as $U$. However, another effect of an increase in the size of the project pool is to drive down the likelihood that a given project is screened. Because only $U$ projects are underpriced, this effect increases underpricing. Thus when $\rho<1 / 2$, and a large fraction of $B$ types has already entered the IPO market, further increasing the size of the project pool can, but need not, decrease the average underpricing of IPOs. This proposition is illustrated in Figure 3 for the case of increased underpricing. 
The next two propositions examines the effect of changing the ex ante distribution of projects in the economy on average IPO quality and expected underpricing in equilibrium.

Proposition 5 In an overheating market equilibrium, average IPO quality decreases with any further increase in the quality of the project pool.

This somewhat surprising result, illustrated in Figure 4, says that average IPO quality decreases in the ex ante quality of projects. This is because a marginal increase in the ex ante number of $G$ projects increases the demand for screening so much that it enables more than the equivalent number of $B$ projects to enter the IPO market. Note that this result only holds for the range of parameter values that support the overheating market equilibrium. As the fraction of $G$ projects increases, inducing more $B$ projects into applying, a limit is reached when all $B$ projects have applied. After this point, the overheating equilibrium no longer holds, and further increases in the quality of the project pool do indeed increase the quality of the IPO pool.

For completeness, we derive the next proposition which holds for reasons similar to those for Proposition 4 and illustrate the relationship in Figure 5.

Proposition 6 In an overheating market equilibrium, when an increase in the quality of the project pool leads also to an increase in the variance of the IPO pool, expected underpricing increases unambiguously. A sufficient, but not necessary, condition for the variance to increase with project pool size is that at least half the projects are good.

The above propositions imply our results about IPO pool quality and underpricing hold not only when the number of projects in the economy increases, but also if the quality of the pool improves. This could happen, for instance, if interest rates drop or a new discovery makes existing projects more valuable. Whether pool size or quality increases, if the increased IPO demand from a larger number of $G$ projects creates a labor shortage, wages go up, resulting in a reduction in the amount/quality of screening which, in turn, encourages more $B$ projects to apply for IPOs, further worsening the labor shortage. This reasoning along with the above propositions provides the following testable implications.

- The amount of screening per project (proxied, for example, by the size of the underwriting syndicate) would be lower in hot markets, while investment banking compensations would be higher.

- The additional heterogeneity of the applicant pool in hot markets due to a larger proportion of $B$ projects would result in more variable accounting profits as well as greater volatility in long run returns. 
- Small or localized shocks to IPO demand are unlikely to impact underpricing as they would not affect screening quality enough to induce entry by a greater proportion of $B$ projects.

- Since $G$ projects always apply for IPOs, and during hot markets a larger proportion of $B$ projects apply, hot markets will be characterized by both higher volume and higher underpricing. This occurs solely because of inelasticity of labor supply, not for any behavioral reason.

- Underpricing should gradually decrease over the life of a hot market as more screening labor gets adequately trained and relaxes the supply constraint.

\subsection{Feedback in hot markets}

We have been consistently interested in the question of whether, keeping the labor supply constant, an exogenous increase in the size of the project pool $N$ (keeping constant the ex ante quality distribution) results in a proportional increase in the number of realized IPOs. In our model, increasing the number of available projects has two effects. The first order effect is that, for every new project, there are $\rho$ new $G$ type projects applying for IPOs and $(1-\rho) \alpha^{*}$ new $B$ types applying. However, if this additional demand for IPOs runs into the labor constraint, screening gets worse which allows a higher proportion of $B$ types to apply. Since this drives many of the results in the paper, we prove it formally in the next proposition.

Proposition 7 In an overheating market equilibrium, a marginal increase in the number of potential projects $(N)$ leads a larger fraction of potential projects to enter the IPO market.

\subsection{Discontinuous transition to hot markets}

So far we have only overheating market solutions where issues are underpriced and screening labor earns positive rents. These conditions correspond to the idea of a "hot" IPO market. Similarly, the idea of a "cold market," from our labor market perspective, corresponds to a market where there is an excess supply of screening labor relative to projects and new issues are sufficiently screened to eliminate under pricing. For some parameter values of our model such equilibria do exist. They are not very interesting from our perspective because they feature a slack labor market whose equilibrium conditions do not constrain the IPO market. Not surprisingly cold markets are supported by low demand for screening, either because there are few potential projects, i.e., low $N$ or 
few good projects, i.e., low $\rho$. What is interesting from our perspective is how the IPO market changes as the supply or quality of projects increases. What happens when these parameters are nudged up just above the level that is consistent with a cold market? Does the price and quality of IPOs shift continuously or does this small nudge produce a discontinuous shift in the character and quality of IPO issues. In this section we show that the shift from cold to hot markets is discontinuous whenever the payoff to entrepreneurs from a high priced IPO, $\beta$, greatly exceed their payoff from their reservation compensation.

Proposition 8 When the potential upside gain to entrepreneurs from an IPO is suffciently high relative to their reservation compensation, i.e., $w<\beta / 2$, there is always an upper threshold of average project quality and quantity beyond which point a discontinuous downward jump in the quality of the IPO applicant pool occurs. More specifically, for all $(N, \rho)$ such that $N \rho \leq \beta /(\beta-w)$ there exists an equilibrium where only good projects attempt to obtain funding and there is no underpricing. For $N \rho>\beta /(\beta-w)$ the probability a firm attempting to obtain IPO funding is good never exceeds $\max \left[w /(\beta-w), \pi^{u p}\right]<1$.

A basic empirical implication of Proposition 8 is that when successful high quality firms can capture supernormal economic gains from the new financing generated by an IPO, e.g., when such firms are investing in a potentially revolutionary technology, the transition between a cold IPO market and a hot market should be quite dramatic, marked by a surge in the quantity and a sharp fall in the quality of IPOs being issued. In contrast, when the potential gains to successful high quality firms are more modest, heating up of the IPO market should be marked by a more measured increase in IPO quantity and fall in quality.

\section{Conclusion}

In this paper we have developed a model of IPO underpricing that endogenizes the cost of screening labor to investment banks. The comparative statics produced by this model are both distinct as well as consistent with many of the stylized facts surrounding hot IPO markets: increased income for investment bankers, high levels of underpricing, a flood of marginal investment projects, and a reduction in underwriting standards. Two directions for extending this work seem promising. One direction is to try to extend the analysis of our specific investment banking problem to a dynamic setting. In such a setting, entrepreneurs with good projects could choose to either issue in hot markets or delay, hoping for less underpricing. Such endogenous timing might cool off hot markets by 
reducing the bunching of IPOs in the aggregate and improve screening. It is worthwhile to note that the incentive for good types to avoid bunching suggested here is opposed to the conclusion of much of the asymmetric information literature (e.g., Admati and Pfleiderer (1988)) which shows that high quality types have an incentive to bunch their activities at a fixed point in time to minimize adverse selection costs. However, there are countervailing incentives to project delay. The better the entrepreneur's investment options, the larger her costs of delay. Thus, delaying this onset of projects could lower the market's evaluation of the quality of the entrepreneur's project. As long as perfect screening is not feasible in later periods, this reduction in perceived quality might discourage high quality firms from delaying projects to avoid the underpricing of hot IPO markets.

A dynamic setting would also provide investment banks with new incentives and opportunities. Notably, they would have incentives to smooth out the cost of skilled labor, and to increase the supply of labor in hot markets. Because, labor contracts are difficult to enforce against workers (see Harris and Holmström (1982)), simply buying forward labor contracts might not be an effective means to stock supply for an anticipated hot market. However, overstaffing in cold market periods combined with building up firm-specific evaluation systems could provide firms with a somewhat captive supply of investment banking labor, and thus allow firms to capture more of the rents from hot markets, while at the same time improving screening in hot markets.

Another direction for extending this analysis is to apply equilibrium supply constraint conditions to other problems in economics which feature third-party screening. Our basic dynamic, under which supply shocks to the screening system leads institutions to rationally (at an individual level) economize on screening, leading more bad types to enter the market, in turn making screening even more costly, etc., could be modeled for other markets. Consider real estate markets or markets for venture capital during a real-estate or tech boom. High quality proposals could increase in volume sufficiently to stretch the screening capacity of traditional lenders or venture capitalists leading them to screen with less experienced labor. The resulting weakening of screening could lead owners of less viable projects to attempt entry, further straining screening and thus encouraging even more low quality firms to enter. Alternatively, consider the problem of a government trying to separate legitimate from illegitimate instances of a novel tax shelter or claim for disaster insurance. The more the tax shelter (claim) is filed, the more difficult it will be for the fixed number of officials to evaluate legitimacy, which implies weaker screening and thus more illegitimate shelters (claims) being attempted, and increased number of illegitimate filings further weakening screening, etc. 
In a dynamic setting, there is another mechanism by which a vicious cycle of screening deterioration can emerge. Consider a case where workers who are not screened will become future screeners. Here poor screening now leads to poor screeners in the future, encouraging more substandard applicants to attempt to obtain positions. In sum, we believe that endogenizing the compensation of screeners both increases the explanatory power of screening models for the IPO market and has the potential to explain many other anomalous results in markets characterized by informational asymmetries. 


\section{Exogenous variables}

\begin{tabular}{ccc}
\hline Variable & Support & Description \\
\hline$\tilde{X}$ & $x \in\{0,1\}$ & Project cash flow \\
$\rho$ & $0 \leq \rho \leq 1$ & Proportion of good projects in economy \\
$\tilde{s}$ & $s \in\{H, L, U\}$ & Underwriter's screening signal \\
$w$ & $w>0$ & Reservation wage of $G$ and $B$ projects \\
$\beta$ & $0 \leq \beta \leq 1$ & Fraction of IPO proceeds to firm net of commission \\
$\gamma$ & $\gamma>0$ & Penalty to underwriter for overpricing \\
$N$ & $N>1 / \rho$ & Size of the available project pool \\
\hline
\end{tabular}

\section{Endogenous variables}

\begin{tabular}{ccc}
\hline Variable & Support & Description \\
\hline$p_{s}$ & $p_{s} \in\left\{p_{H}, p_{L}\right\}$ & Offer price of IPO (conditional on screening) \\
$\alpha$ & $0 \leq \alpha \leq 1$ & Proportion of $B$ projects in applicant pool \\
$\pi$ & $\rho \leq \pi \leq 1$ & Average IPO quality \\
$\eta$ & $0 \leq \eta \leq 1$ & Optimal amount of underwriter screening \\
$\theta$ & $\theta \geq 0$ & Equilibrium unit price of screening labor \\
\hline
\end{tabular}

Table 1: Description of variables 


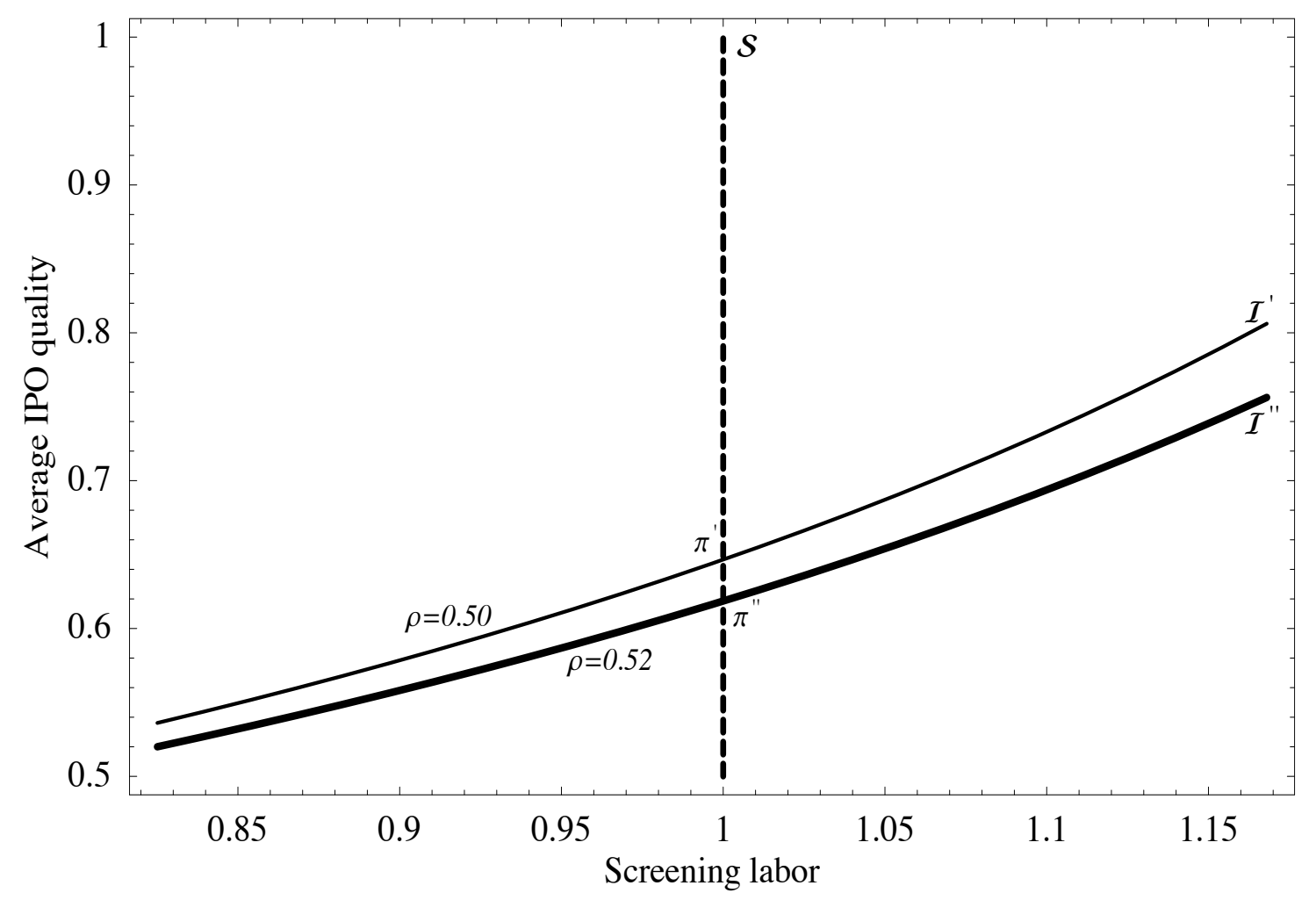

Figure 1: Inelastic labor supply: Average IPO quality vs. screening labor demand 


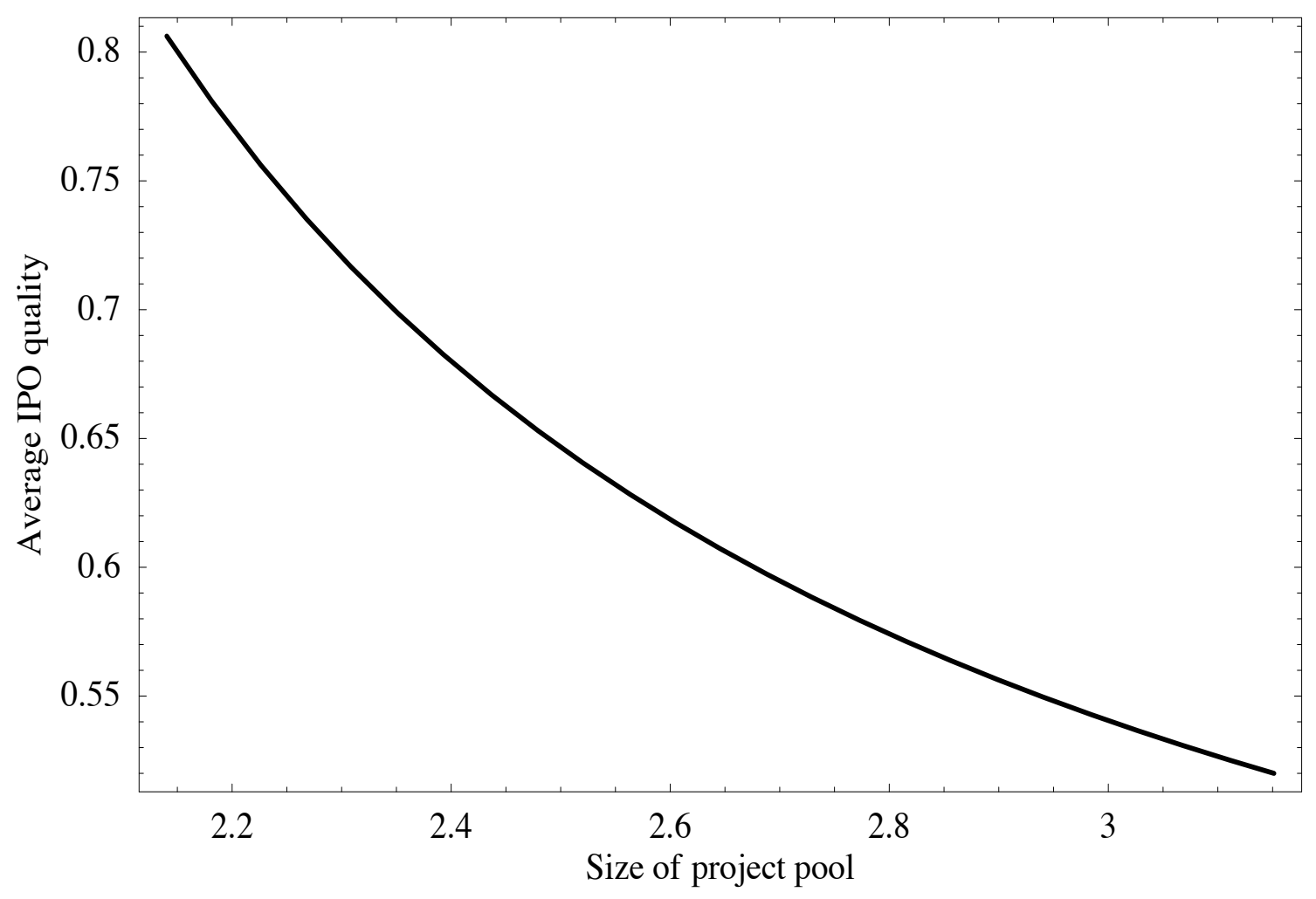

Figure 2: Average IPO quality, $\pi$ vs. project pool size, $N$ 


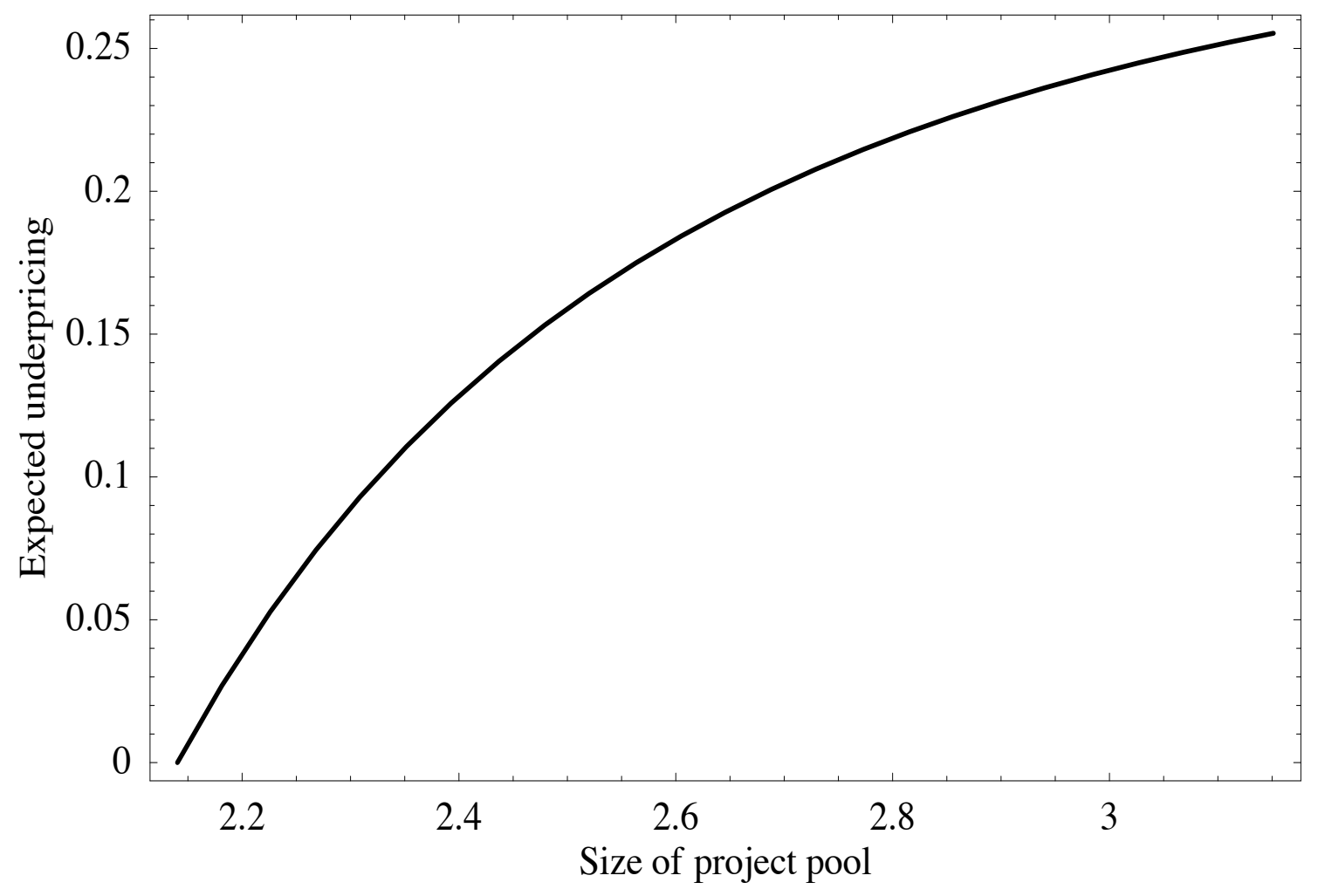

Figure 3: Expected underpricing vs. project pool size, $N$ 


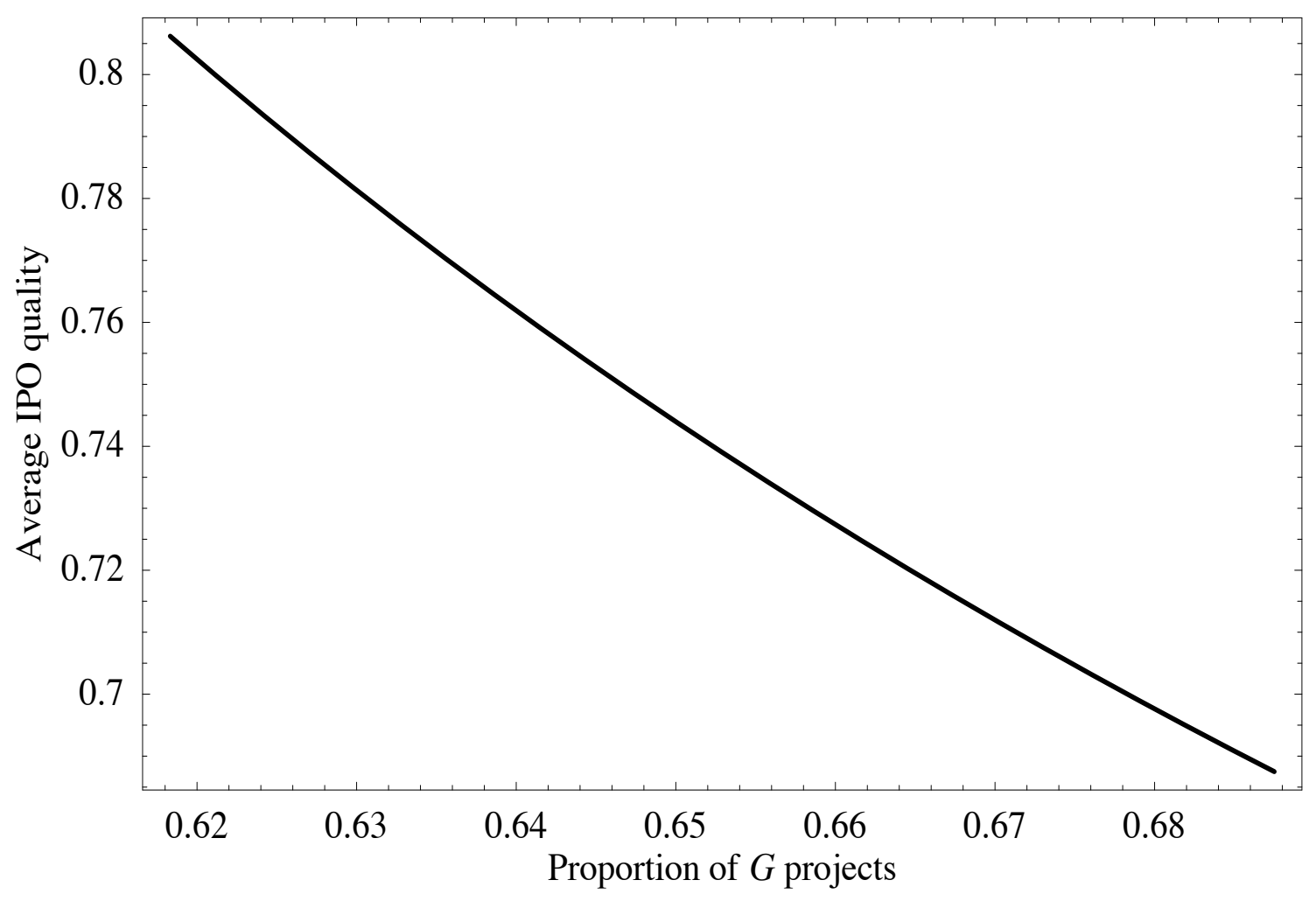

Figure 4: Average IPO quality, $\pi$ vs. applicant pool quality, $\rho$ 


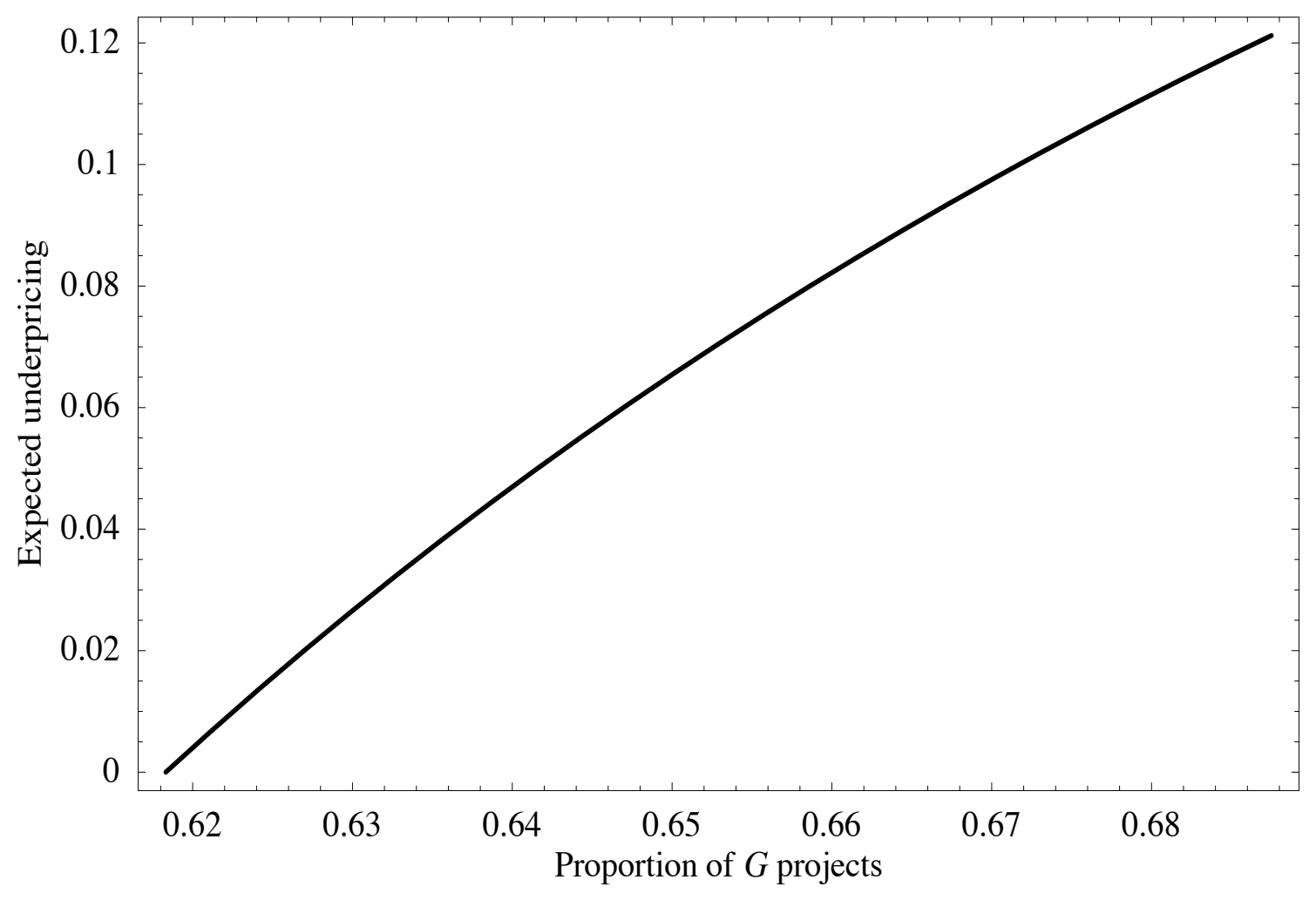

Figure 5: Expected underpricing vs. applicant pool quality, $\rho$ 


\section{Appendix A}

\section{Probabilities}

As is clear from the text of the paper, we need consider only equilibria where all $G$ projects apply for an IPO and a proportion $\alpha$ of $B$ projects apply. The priors of the underwriter in any such equilibrium are

$$
\begin{aligned}
\pi & =\frac{\rho}{\rho+(1-\rho) \alpha} \\
\text { and } 1-\pi & =\frac{1-\rho) \alpha}{\rho+(1-\rho) \alpha} .
\end{aligned}
$$

Using the priors and the signal structure, it is easy to derive the following posterior probabilities:

$$
\begin{aligned}
P(G \mid H) & =1, \\
P(B \mid H) & =0, \\
P(G \mid L) & =0, \\
P(B \mid L) & =1, \\
P(G \mid U) & =\pi, \\
\text { and } P(B \mid U) & =1-\pi .
\end{aligned}
$$

\section{Rationale for Assumptions 1 and 2}

For Assumption 1, we need that when all $B$ projects enter the IPO market, if underwriters do not screen at all, then it is better to underprice projects screened as $U$. Therefore, we require that the price set for $U$ projects under these conditions is the underpricing solution. In other words, we need:

$$
\begin{aligned}
& \left.\frac{1}{2 \gamma(1-\pi)}\right|_{\pi=\rho}<\left.\pi\right|_{\pi=\rho}, \\
& \Rightarrow 2 \gamma(1-\rho) \rho>1, \text { which is Assumption } 1 .
\end{aligned}
$$

For Assumption 2, we need to ensure that if underwriters do not screen at all, i.e. choose $\eta=0$, and if there is no underpricing, all $B$ projects will always apply for 
screening, i.e., we need that:

$$
\begin{aligned}
E_{B}(\eta=0) & =\left.\beta p_{U}^{*}\right|_{\alpha=1}>w \\
\Rightarrow \beta \rho & >w, \text { which is Assumption } 2 .
\end{aligned}
$$

\section{Proof of Proposition 1}

Suppose the probability of issuance for $G$ entrepreneurs is less than 1 but positive. In this case $G$ entrepreneurs must be indifferent to issuing. The fact that the payoff from not issuing is independent of the project type, and the fact that the payoff from issuing is higher for a $G$ project, show that the indifference of $G$ entrepreneurs implies a lower payoff from issuing than not issuing for $B$ projects. Thus, sequential rationality requires that $B$ entrepreneurs not issue. However, Bayes rule then implies that in equilibrium $\pi=1$. Thus by $(5), p_{U}^{*}=1$, which implies that $E_{G}(\eta)=1, \forall \eta$. This implies by Assumption 2 that $E_{G}>w$, which in turn implies by sequential rationality that all $G$ entrepreneurs issue with probability 1 . This contradiction establishes our result. Next, turn to the case where entrepreneurs with good projects never issue. In this case because of the relative preference for issuing when the project is good, it must be the case that no entrepreneurs issue. In this case issuing is off the equilibrium path. However, a standard refinement, i.e., the D1 refinement in Cho and Kreps (1987) requires that when one type has a greater preference for an off equilibrium action than another type over all possible responses by the uninformed party, all weight be placed on that type choosing the off equilibrium action. This restriction would be for off-equilibrium beliefs to place all the weight on the $G$ entrepreneurs issuing. Under this assumption, using exactly the same reasoning as we used above, we see that all entrepreneurs with $G$ projects issue with probability 1 . This contradiction establishes the result.

\section{Proof of Proposition 2}

Note that aggregate demand for screening labor equals $N \eta^{*}[\rho+(1-\rho) \alpha]$. Given Assumption 3, at $\eta^{*}=1$, aggregate demand exceeds supply and thus is inconsistent with the equilibrium supply conditions. If $\eta^{*}=0$, screening labor demand is less than supply and thus, the price of screening labor equals 0 . In this case, the only way for $\eta=0$ to be optimal is if the equilibrium $\pi=1$. But if $\pi=1$, then $p_{U}^{*}=1$ and by Assumption $2, E_{B}>w$. But this implies that all $B$ entrepreneurs will prefer to issue. In that case, $\pi=1$ is not consistent with Bayes rule. This contradiction establishes the result. 


\section{Comparative Statics: Proofs of Propositions 3 through 6}

To determine the bounds on $N$ for which this equilibrium exists, we use the fact that $\pi^{*}$ has to be between $\rho$ and 1 . Also, we need that for underpricing to prevail, $\pi<\pi^{\text {up }}$. In other words, we require

$$
\rho<\pi^{*}<\pi^{\text {up }}<1
$$

As will be confirmed shortly, $\pi^{*}$ is a decreasing function of $N$. Therefore, the above bounds on $\pi^{*}$ can be rewritten as bounds on $N$ as

$$
\begin{aligned}
& N_{1}^{\text {up }}<N<\frac{\beta}{\beta-2 \gamma w(1-\rho)}, \\
& \text { where } N_{1}^{\text {up }} \text { solves } \pi^{*}=\pi^{\text {up }} \text {. }
\end{aligned}
$$

From equation (14) of the text, we have

$$
\pi^{*}=\frac{N \rho(2 \gamma w-\beta)}{(2 \gamma w N \rho-\beta)} .
$$

Differentiating $\pi^{*}$ with respect to $N$, we have

$$
\frac{\partial \pi^{*}}{\partial N}=\frac{-\beta \rho(2 \gamma w-\beta)}{(2 N \gamma w \rho-\beta)^{2}}
$$

The equilibrium level of underwriter screening is obtained by substituting from equation (14) into (13) as follows:

$$
\eta^{*}=\frac{1}{N \rho}\left[\frac{(2 \gamma w-\beta) N \rho}{(2 \gamma w-\beta) N \rho+\beta(N \rho-1)}\right] .
$$

Therefore, for $\eta^{*}$ to be less than one, we require that $(2 \gamma w-\beta)$ be positive, which in

turn implies that $\frac{\partial \pi^{*}}{\partial N}<0$ (we have also used Assumption 3 here).

Using the definitions of $\pi^{*}$ and $\eta^{*}$,and simplifying, we can write expected underpricing in this equilibrium as

$$
\begin{aligned}
E_{u p} & =\left(1-\eta^{*}\right)\left[1-\frac{1}{2 \gamma \pi^{*}\left(1-\pi^{*}\right)}\right] \\
& =\frac{2 \gamma w \pi^{*}\left(1-\pi^{*}\right)-w}{\beta \pi^{*}}
\end{aligned}
$$

By the chain rule of differentiation, we can write

$$
\frac{\partial E_{u p}}{\partial N}=\frac{\partial E_{u p}}{\partial \pi^{*}} \frac{\partial \pi^{*}}{\partial N}
$$


From (A-8), we have

$$
\frac{\partial E_{u p}}{\partial \pi^{*}}=\frac{w\left(1-2 \gamma \pi^{* 2}\right)}{\beta \pi^{* 2}} .
$$

The above expression cannot be unambiguously signed in general, while from above we know that $\frac{\partial \pi^{*}}{\partial N}<0$. In other words, we cannot unambiguously determine the direction of the relationship between expected underpricing and $N$.

To derive a sufficient condition for unambiguously signing the above derivative, we evaluate $\frac{\partial E_{u p}}{\partial \pi^{*}}$ from (A-10) at $\pi^{*}=\pi^{\text {up }}$ and $\pi^{*}=\rho$, the extremal points.

It is easy to see that at $\pi^{*}=\pi^{\text {up }}, \frac{\partial E_{u p}}{\partial \pi^{*}}<0$. At $\pi^{*}=\rho,(\mathrm{A}-10)$ evaluates to

$$
\frac{w\left(1-2 \gamma \rho^{2}\right)}{\beta \rho^{2}} .
$$

Starting from Assumption 1, we can write the following series of inequalities:

$$
1<2 \gamma \rho(1-\rho) \Rightarrow 1-2 \gamma \rho^{2}<2 \gamma \rho-4 \gamma \rho^{2}=2 \gamma \rho(1-2 \rho) .
$$

Using equations (A-11) and (A-12), it is easy to deduce that if $\rho>0.5, \frac{\partial E_{u p}}{\partial \pi^{*}}<0$. In other words, $\rho>0.5$ is a sufficient condition for expected underpricing to increase with the size of the project pool.

It is also easy to verify that the derivative of $\pi^{*}$ with respect to $\rho$ is

$$
\frac{\partial \pi^{*}}{\partial \rho}=\frac{-N \beta(2 \gamma w-\beta)}{(2 N \gamma w \rho-\beta)^{2}}<0 .
$$

Once again using the chain rule, we have

$$
\frac{\partial E_{u p}}{\partial \rho}=\frac{\partial E_{u p}}{\partial \pi^{*}} \frac{\partial \pi^{*}}{\partial \rho} .
$$

Once again, this expression cannot be unambiguously signed in general, but when $\rho>0.5$, expected underpricing is increasing in ex-ante project quality.

\section{Proof of Proposition 7}

The total number of IPOs in equilibrium is

$$
V=N[\rho+(1-\rho) \alpha]=\frac{N \rho}{\pi^{*}} .
$$


Differentiating (A-15) with respect to $N$, we have

$$
\frac{\partial V}{\partial N}=\frac{\rho}{\pi^{*}}-\frac{N \rho}{\pi^{* 2}}\left(\frac{\partial \pi^{*}}{\partial N}\right)
$$

Substituting from (A-6) into (A-16), we have

$$
\frac{\partial V}{\partial N}=\frac{\rho}{\pi^{*}}\left[1+\frac{\beta}{(2 N \gamma w \rho-\beta)}\right]>\frac{\rho}{\pi^{*}}
$$

The first factor, $\frac{\rho}{\pi^{*}}$ is simply the equilibrium proportion of realized IPOs to available projects, and is the first order effect of an exogenous increase in the total number of projects. The second factor is the multiplier, the magnitude of which reflects the feedback effect on the number of IPOs, which arises due to the dependence of $\alpha^{*}$, or equivalently, $\pi^{*}$ on $N$. Note that the feedback multiplier is a decreasing function of the number of projects, $N$, for a fixed total supply of labor.

\section{Proof of Proposition 8}

First, note that if the issue is priced after an uninformative signal at 1 , the payoff to a $B$-type project from attempting to issue an IPO is $\beta(1-\eta) 1$; the payoff from not attempting to fund the project is $w$. Thus, it is incentive compatible for a $B$ type not to attempt an IPO if and only if the following condition is satisfied

$$
\beta(1-\eta) \leq w
$$

If only $G$ projects attempt to obtain funding, and projects are screened at rate $\eta$ then the total demand for screening labor equals $N \eta \rho$. For labor markets to clear we must have this total demand less than supply, which equals 1 . Thus, labor market clearing is satisfied if and only if

$$
N \eta \rho \leq 1
$$

$(N, \rho)$ pairs can satisfy $(\mathrm{A}-18)$ and $(\mathrm{A}-19)$ if and only if $N \rho \leq \beta /(\beta-w)$. Thus, when $N \rho>\beta /(\beta-w)$ no equilibrium exists in which only good firms attempt IPOs.

The proposition asserts that when $N \rho>\beta /(\beta-w)$ there is an upper bound, $\max \left[w /(\beta-w), \pi^{\mathrm{up}}\right]<1$ on IPO quality, $\pi$, that holds regardless of how close the $(N, \rho)$ pair is the region $N \rho \leq \beta /(\beta-w)$ in which IPO quality is 1 . This propostion would not be disconfirmed by any equilbirum in which all $B$-types attempt IPOs as in this case, the quality of the applicant pool $\pi$ would equal $\rho$, less than the stipulated upper bound. Thus, the proposition can only be disconfirmed by an equilibrium in which only 
a fraction of $B$ projects attempt to obtain financing. This outcome can only hold if $B$ projects do not strictly gain from issuing, i.e.,

$$
\beta(1-\eta) p_{U}^{*}-w \leq 0
$$

Moreover, to disconfirm the proposition, average pool quality must be greater than $\pi^{\text {up }}$. From the expressions for issue pricing, (5) and (4), the issue is not underpriced in this case, i.e., $p_{U}^{*}=\pi$. Thus, in an equilbrium disconfirming the propostion, the payoff to a $B$ project attempting to issue an IPO is given by

$$
\beta(1-\eta) \pi
$$

Thus, to show that no equilbrium exists that disconfirms the propostion we need only show that for all $\pi>w /(\beta-w)$, the net gain from issuing, i.e. the payoff less the cost without underpricing is positive, i.e.,

$$
\beta(1-\eta) \pi-w>0
$$

Now, because some bad firms are entering the market, $V_{I}^{*}(\pi)>V_{U}^{*}(\pi)$, which implies that the price of screening labor, $\theta$ is positive, and hence the screening labor market cannot be slack. This fact in turn implies that $N \eta \rho=\pi$. Using this condition to subsitute for $\eta$ in (A-22),we see that the net gain to a bad firm from attempting to issue is given by

$$
\beta\left(1-\frac{\pi}{N \rho}\right) \pi-w .
$$

Now, because $N \rho>\beta /(\beta-w)$, we know that

$$
\beta\left(1-\frac{\pi}{N \rho}\right) \pi-w>\operatorname{quad}(\pi)
$$

where

$$
\operatorname{quad}(\pi) \equiv(\beta-\pi(\beta-w)) \pi-w
$$

Further, $\operatorname{quad}(\cdot)$ is a concave quadratic with roots at $w /(\beta-w)$ and 1 . Hence, for all $\pi \in[w /(\beta-w), 1], \operatorname{quad}(\pi) \geq 0$. From this fact and (A-24), we conclude that for all $\pi \in[w /(\beta-w), 1],(\mathrm{A}-22)$ holds. 


\section{Appendix B}

\section{Overview}

Using the model developed in this paper, we have demonstrated a key result in Proposition 5 that in a partially effective screening equilibrium featuring underpricing, "good IPOs draw in bad", whereby IPO quality decreases in the quality of the project pool. In this appendix we demonstrate that this key result holds in the IPO underpricing model due to Rock (1986) (the "Rock model" hereafter), which we believe is quite representative of theoretical literature on IPOs.

\section{The modified model}

We begin by considering a simplified version of the Rock model. Associated with each project (firm) in our model is an informed investor. This investor knows the quality of the issue with certainty. In other words, even if underwriter screening produces an uninformative signal, $U$, the informed investor can perfectly distinguish $G$ projects from $B$ projects in the project pool. Both types of investors, informed and uninformed are risk-neutral and capital constrained. Underwriters price and issue shares to both types of investors, anticipating their optimal participation in the IPO. The relative wealth of the informed and uninformed investors is such that if they both bid for an IPO issue, rationing will assign a fraction $\zeta$ of the issue to the informed and the remaining to the uninformed. ${ }^{17}$

\section{Pricing}

When underwriter screening generates a $H$ or a $L$ signal, IPO prices are identical to those in the base model contained in the text. The only issue is how a project screened as a $U$ is priced in this context. To derive the price $p_{U}$, note that underwriters and issuing firms prefer as high a price as possible. However, because of their informational advantage, informed investors invest only in IPOs that they know are $G$ projects. They do not participate at all in $B$ projects. Thus, IPO underpricing in this model is a mechanism to provide an incentive to the uninformed investors to invest, knowing full

\footnotetext{
${ }^{17}$ There are two differences between our simplified setup here and that of the original Rock model. First, Rock assumes that project quality is continuously distributed, whereas we assume a discrete distribution over two possible quality types. Second, investors in the Rock model are risk averse, while they are risk neutral in ours. Barring these two innocuous deviations from the original model, it will be seen below that the spirit of the Rock model is very much preserved as far as pricing is concerned.
} 
well that sometimes they will be investing in bad IPOs. Uninformed investors will seek to make at least a non-negative expected profit from their IPO investment in a $U$ project, which can be expressed as

$$
\begin{array}{r}
(1-\pi)\left(0-p_{U}\right)+\pi\left[(1-\zeta)\left(1-p_{U}\right)\right] \geq 0 \\
\Rightarrow p_{U} \leq p_{U}^{*}(\pi)=\frac{\pi(1-\zeta)}{(1-\pi \zeta)}
\end{array}
$$

Given that underwriters and issuers prefer the highest possible price, it is easy to see that the optimal price of a $U$ project is set to be $p_{U}^{*}(\pi)$. It can easily be verified that $p_{U}^{*}<\pi$ as long as there is an informed investor $(\zeta>0)$, and the quality of the project pool is uncertain $(\rho<\pi<1)$. In other words, the price in (B-1) is at a discount to the fair issue price $\pi$, and there is underpricing.

\section{Equilibrium}

We now proceed to investigate a partially effective screening equilibrium featuring underpricing according to (B-1). The relevant conditions are

$$
\begin{aligned}
\beta(1-\eta) p_{U}^{*}(\pi) & =w \\
N \eta \rho & =\pi \\
V_{I}^{*}(\pi)-\theta & =V_{U}^{*}(\pi) \\
\text { and } p_{U}^{*}(\pi) & =\frac{\pi(1-\zeta)}{(1-\pi \zeta)} .
\end{aligned}
$$

After substitution of the price $p_{U}^{*}(\pi)$, and simplification, we can write the optimal IPO quality in this setup as the solution to

$$
g\left(\pi^{*}, \rho\right) \equiv \pi^{* 2} \beta(1-\zeta)-\pi^{*} N \rho[\beta(1-\zeta)+w \zeta]+N \rho w=0
$$

The pair of solutions to the quadratic in (B-3) is given by

$$
\pi^{*}=\frac{N \rho[\beta(1-\zeta)+w \zeta] \pm \sqrt{N^{2} \rho^{2}[\beta(1-\zeta)+w \zeta]^{2}-4 N \rho w \beta(1-\zeta)}}{2 \beta(1-\zeta)}
$$

\section{IPO quality versus project quality}

We are interested in the behavior of average IPO quality as the ex-ante quality of the project pool changes. We therefore derive the partial derivative of $\pi^{*}$ with respect to $\rho$ 
below.

Applying the implicit function theorem to the quadratic in (B-3), we can write

$$
\begin{aligned}
\frac{\partial \pi^{*}}{\partial \rho} & =-\frac{\left(\frac{\partial g}{\partial \rho}\right)}{\left(\frac{\partial g}{\partial \pi^{*}}\right)}, \\
\text { where } \frac{\partial g}{\partial \rho} & =-\pi^{*} N[\beta(1-\zeta)+w \zeta]+N w \\
& =-\frac{\pi^{* 2} \beta(1-\zeta)}{\rho}, \\
\text { and } \frac{\partial g}{\partial \pi^{*}} & =2 \pi^{*} \beta(1-\zeta)-N \rho[\beta(1-\zeta)+w \zeta] \\
& = \pm \sqrt{N^{2} \rho^{2}[\beta(1-\zeta)+w \zeta]^{2}-4 N \rho w \beta(1-\zeta)}
\end{aligned}
$$

It is evident from the above equations that $\frac{\partial g}{\partial \rho}$ is always negative while $\frac{\partial g}{\partial \pi^{*}}$ is positive at the larger root and negative at the smaller root. Then, equation (B-5) implies that as long as $\pi^{*}$ is given by the smaller root of the quadratic, $\frac{\partial \pi^{*}}{\partial \rho}$ is negative, and for the larger root of the quadratic, $\frac{\partial \pi^{*}}{\partial \rho}$ is positive. Thus, we have proved that over a range of ex-ante project quality, we have average IPO quality decreasing with project pool quality. It only remains to derive the supports of $\rho$ over which each of the roots is valid. Before we do so, it is useful to examine a diagram of IPO quality versus project pool quality.

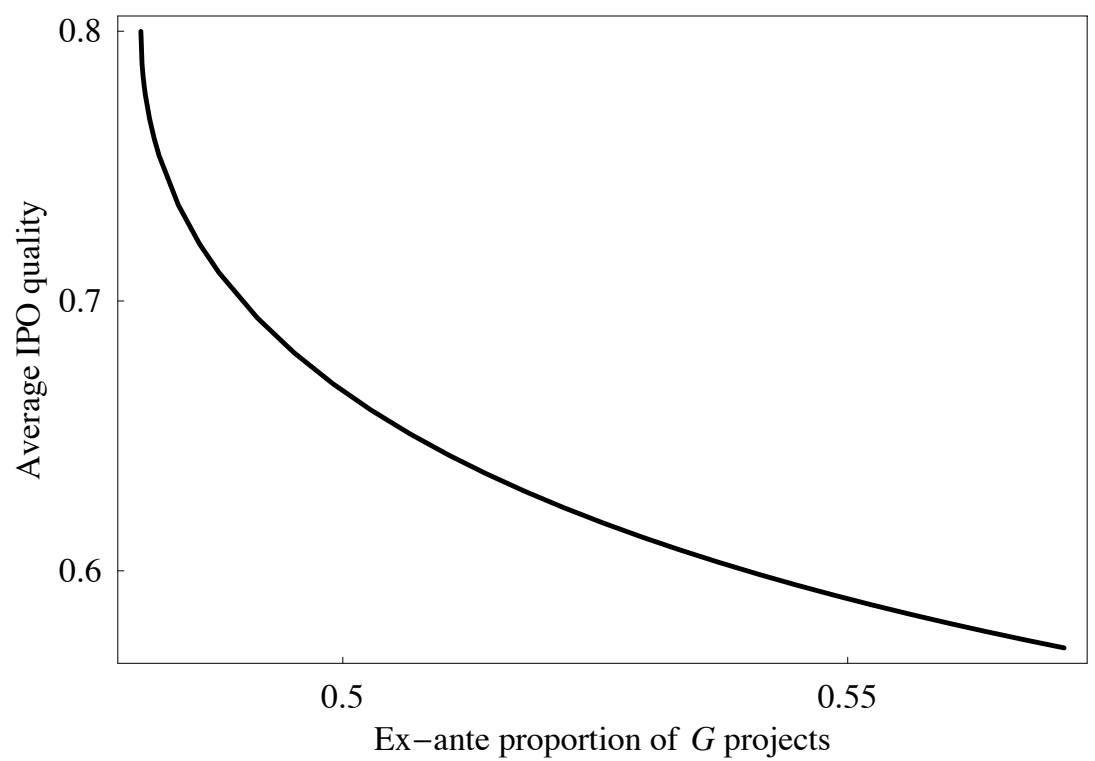

Figure B-1: Average IPO quality, $\pi$ vs. the ex-ante proportion of $G$ projects, $\rho$

From figure B-1, we observe that when we embed the Rock model of underpricing in our IPO and labor market model, we obtain results exactly similar to those obtained 
using the legal risk framework of underpricing we have used.

\section{Technical details}

In this section we establish the conditions for existence of the above mentioned solutions, and identify the ranges of $\rho$ over which each solution applies.

We start first with equation (B-3). This is a convex quadratic in $\pi$. The equation has two equal, real roots at a minimum value of $\rho$ given by

$$
\hat{\rho}=\frac{4 \beta w(1-\zeta)}{N[\beta(1-\zeta)+w \zeta]^{2}} .
$$

The (two identical) solutions for $\pi^{*}$ at this value of $\hat{\rho}$ are

$$
\hat{\pi^{*}}=\frac{2 w}{[\beta(1-\zeta)+w \zeta]} .
$$

Since we require $\rho<\pi<1$, we restrict our analysis to the case where $\hat{\pi}^{*}>\hat{\rho}$. As $\rho$ increases beyond $\hat{\rho}$, the smaller solution in (B-4) decreases, and the larger solution increases towards 1 . Therefore, it is evident that the support of $\rho$ for which the larger solution is valid is between $\hat{\rho}$ and $\frac{\beta}{N(\beta-w)}$. This last quantity is the value of $\rho$ for which $\hat{\pi}^{*}=1$. Considering the smaller solution, the maximum value of $\rho$ at which $\hat{\pi}^{*}$ attains its lowest possible value, $\rho$, is given by $\frac{N w}{N[\beta(1-\zeta)+w \zeta]-\beta(1-\zeta))}$. Therefore, the support of $\rho$ for which the smaller solution is valid is between $\hat{\rho}$ and $\frac{N w}{N[\beta(1-\zeta)+w \zeta]-\beta(1-\zeta))}$.

\section{Discussion}

In the above analysis, we have proved that our principal conclusion from Proposition 5 of the text holds true for some parametric spaces when underpricing is modeled as in Rock (1986). In fact, we can say more. It can be proved that our result holds for any issue pricing function $p_{U}(\pi)$ as long as the following general conditions hold: ${ }^{18}$

1. $p_{U}(\pi) \leq \pi$.

2. $p_{U}($.$) is strictly increasing and continuous.$

3. $p_{U}(1)=1$.

4. The quality of the project pool affects the IPO issue price only through their effect on the cash flow distribution of the project.

\footnotetext{
${ }^{18}$ In the interest of brevity, we have omitted a proof of this assertion. A technical proof is available from the authors upon request.
} 
5. $p_{U}($.$) is continuously differentiable at \pi=1$, with $p^{\prime}(1)>0$.

Condition 1 simply requires that under the uninformative signal, the issue price satisfies rational expectations in that the price is less than or equal to the market's assessment of the project based on Bayes' rule. Condition 2 states that the issue price increases when the distribution of cash flows improves in the sense of first order stochastic dominance. Condition 3 requires that when only $G$ projects undertake IPOs, the market correctly assesses their value and does not underprice. Condition 4 requires that the price of the issue does not depend directly on project pool quality, and that all such dependence is only through the equilibrium conditions.

We believe that almost any economically reasonable pricing function will satisfy conditions 1 through 4, and that our technical condition of smoothness, condition 5 is quite standard. It is hard to imagine a rational model of IPO pricing that would violate condition 1, as such a model would contradict the rationality of outside investors. Condition 2 would only be violated if ceteris paribus increases in the project cash flow (in the sense of first order stochastic dominance) lead to an unchanged or lower issue price. Condition 3 requires that when there is no uncertainty regarding project quality, there in no underpricing. We cannot think of a sensible IPO pricing model that would violate conditions 2 and 3.

Condition 4 is the most stringent condition we require to be satisfied. However, it is both necessary and sensible. For the necessity of the condition, note that one can trivially reverse the conclusions of our analysis if one assumes an arbitrary form of dependence of issue prices on the quality of the project pool. For instance, suppose one assumes that when the project pool quality exceeds a certain threshold, the market prices all issues at zero. In this case, increasing the quality of the pool will not lead bad projects to attempt to issue. In fact, even good projects will not prefer to issue when project pool quality reaches this threshold. However, assuming that markets price an issue dramatically lower, holding the quality of projects actually undertaking IPOs fixed, because the quality of projects that might issue has increased does not seem consistent with any theory of underpricing we know of, or can conceive of. In fact, the only models we know of in which project pool quality has a pricing effect independent of the quality of the applicant pool are non-Bayesian ambiguity models as in Easley and O'Hara (2005). However, even in such a model (though not covered by our above general conditions), one can show numerically that the comparative static result of Proposition 5 still holds. ${ }^{19}$

\footnotetext{
${ }^{19}$ A Mathematica file with these numerical comparative statics is available upon request.
} 


\section{References}

Admati, A. R., and P. Pfleiderer, 1988, "A theory of intraday patterns: price and volume variability," Review of Financial Studies, 1, 3-40.

Allen, F., and G. R. Faulhaber, 1989, "Signalling by underpricing in the IPO market," Journal of Financial Economics, 23, 303-323.

Benveniste, L. M., W. Busaba, and W. J. Wilhelm, 2002, "Information Externalities and the Role of Underwriters in Primary Equity Markets," Journal of Financial Intermediation, 11, 61-86.

Benveniste, L. M., A. Ljungqvist, W. J. Wilhelm, and X. Yu, 2003, "Evidence of information spillovers in the production of investment banking services," Journal of Finance, $58,577-608$.

Benveniste, L. M., and P. A. Spindt, 1989, "How investment bankers determine the offer price and allocation of new issues," Journal of Financial Economics, 24, 343-361.

Chen, H.-C., and J. R. Ritter, 2000, "The Seven Percent Solution," Journal of Finance, $55,1105-1131$.

Cho, I.-K., and D. M. Kreps, 1987, "Signaling games and stable equilibria," Quarterly Journal of Economics, 102, 179-221.

Cornelli, F., and D. Goldreich, 2001, "Bookbuilding and strategic allocation," Journal of Finance, 56, 2337-2370.

Corwin, S. A., and P. Schultz, 2005, "The role of IPO underwriting syndicates: Pricing, information production, and underwriter competition," Journal of Finance, 60, 443486.

de Meza, D., and D. C. Webb, 1987, "Too much investment: A Problem of Asymmetric Information," Quarterly Journal of Economics, 102, 281-292.

Easley, D., and M. O'Hara, 2005, "Regulation and return: The role of ambiguity," Cornell University working paper.

Harris, M., and B. Holmström, 1982, "A theory of wage dynamics," The Review of Economic Studies, 49, 315-333.

Hermalin, B., and M. L. Katz, 1991, "Moral hazard and verifiability: The effects of renegotiation in agency," Econometrica, 6, 1735-1753. 
Hughes, P. J., and A. V. Thakor, 1992, "Litigation risk, intermediation and the underpricing of initial public offerings," Review of Financial Studies, 5, 709-742.

Ljungqvist, A. P., and W. J. Wilhelm, 2003, "IPO Pricing and the Dot-Com Bubble," Journal of Finance, 58, 723-752.

Loughran, T., and J. R. Ritter, 2002, "Why don't issuers get upset about leaving money on the table in IPOs?," Review of Financial Studies, 15, 413-443.

Lowry, M., and G. W. Schwert, 2002, "IPO market cycles: Bubbles or sequential learning," Journal of Finance, 57, 1171-1200.

Lowry, M., and S. Shu, 2002, "Litigation risk and IPO underpricing," Journal of Financial Economics, 65, 309-355.

Michelacci, C., and J. Suarez, 2004, "Business Creation and the Stock Market," Review of Economic Studies, 72, 459-481.

Pastor, L., and P. Veronesi, 2005, "Rational IPO Waves," Journal of Finance, 60, 1713 1757.

Rock, K., 1986, "Why new issues are underpriced," Journal of Financial Economics, 15, $187-212$.

Ruckes, M., 2004, "Bank competition and credit standards," Review of Financial Studies, 17, 1073-1102.

Welch, I., 1989, "Seasoned offerings, imitation costs, and the underpricing of initial public offerings," Journal of Finance, 44, 421-449. 